\title{
How to differentiate by price: Proposal for a five-dimensional mode
}

Einar Iveroth, Alf Westelius, Carl-Johan Petri, Nils-Göran Olve, Mathias Cöster and Fredrik

Nilsson

\section{Linköping University Post Print}

\section{Tweet}

N.B.: When citing this work, cite the original article.

Original Publication:

Einar Iveroth, Alf Westelius, Carl-Johan Petri, Nils-Göran Olve, Mathias Cöster and Fredrik Nilsson, How to differentiate by price: Proposal for a five-dimensional mode, 2013, European Management Journal, (31), 2, 109-123.

http://dx.doi.org/10.1016/j.emj.2012.06.007

Copyright: Elsevier http://www.elsevier.com/

Postprint available at: Linköping University Electronic Press http://urn.kb.se/resolve?urn=urn:nbn:se:liu:diva-82102 


\title{
How to differentiate by price: proposal for a five-dimensional model
}

\author{
Einar Iveroth $^{\mathrm{a}, \mathrm{b}}$, Alf Westelius ${ }^{\mathrm{a}}$, Carl-Johan Petri ${ }^{\mathrm{a}}$, Nils-Göran Olve ${ }^{\mathrm{a}, \mathrm{b}, \mathrm{c}}$, Mathias Cöster ${ }^{\mathrm{d}}$, Fredrik Nilsson ${ }^{\mathrm{b}}$ \\ ${ }^{a}$ EIS, Department of Management and Engineering, Linköping University, SE-581 83 Linköping, \\ Sweden \\ ${ }^{b}$ Uppsala University, Department of Business Studies, Box 513, SE-751 20 Uppsala, Sweden \\ c Jönköping University, SE-551 11 Jönköping, Sweden \\ ${ }^{\mathrm{d}}$ Gotland University, SE-621 67 Visby, Sweden
}

\begin{abstract}
The purpose of this article is to analyse the repertoire of possible price models that organisations may deploy for their products and services. This is attained by developing the SBIFT model that suggests that organisations can differentiate by price along five dimensions. Previous research on pricing has been dispersed across different academic disciplines. This article offers a more integrated perspective, derived from earlier theory as well as discussions in a collaborative research project with the international telecom company Ericsson. The model can be used as a tool for price modelling in a descriptive and prescriptive sense. Altogether, this article uncovers implicit features of price models, and by doing so it illustrates how an organisation can differentiate and re-invent their offering based on price.
\end{abstract}

Keywords: price, pricing, price differentiation, price model, collaborative research, strategy

\section{Introduction}

How organisations charge for their products and services is a vital strategic issue as it ultimately affects their performance (Dutta et al., 2003). The success of companies like Google and Ryanair is in part due to their capacity to differentiate by price, and by doing so they can diverge from the industry standard and increase their revenues.

However, price modelling has become increasingly complex as information technology spurs innovative products and service, and as globalisation opens up new markets. For example, Piercy et al. (2010) argue that pricing should move from being a simple tactical tool into being a strategic tool that can change customer behaviour as well as spawn new market opportunities. To do so is, however, not an easy task since pricing research is dispersed across different disciplines (Diamantopoulos, 1991; Ingenbleek, 2007; Ng, 2008) and pricing is in practice often performed with a piecemeal and fragmented approach (Hinterhuber, 2004; Marn et al., 2004; Piercy et al., 2010). Because of this, there is a need for research that explores and makes sense of the repertoire of possible price models that organisations may deploy for their products and services (Ng, 2010).

As a response to such problems, this article develops the SBIFT model that suggests that organisations can differentiate by price along five dimensions. This overarching model for price models can be used for both descriptive and prescriptive purposes and is the outcome of a collaborative research project with the company Ericsson, a world-leading provider of telecommunications equipment and services.

In their business, Ericsson have a variety of customers ranging from single companies to national governments, and their products and services are also diversified, from specific innovative phone equipment to whole systems of telecom infrastructure with adjacent services. As a result, price 
modelling is in many cases a challenge for Ericsson, and the speed of development in the telecom industry does not make it less complex (such problems are commonly shared by others). From Ericsson's point of view, there is a growing interest in obtaining an overview of alternative price models, and a need for a tool to help them to differentiate by price. With this backdrop, a research project was started that explored the question: how can price models be used to differentiate a company's offerings, and what kinds of different configurations of price models may exist? (See section 4.1 for a definition of price model.) The answer to the research question is the five-dimensional SBIFT model presented in this article.

The article is organised as follows. The next section gives a theoretical overview of pricing. The subsequent sections describe the research methodology and the collaborative research approach. This is followed by the findings that are divided into two parts. The first part presents the SBIFT model and the second part applies the model to Google AdWords and Ryanair. The article ends with a broader discussion, managerial implications, and conclusions that show how the SBIFT model contributes to both theory and practice.

\section{Theoretical background}

\subsection{Pricing research}

The field of pricing research consists of "pockets" of high-quality and rigorous research (Diamantopoulos and Mathews, 1995; Ingenbleek, 2007; Ng, 2008). For example, Ng describes pricing as consisting of many individual disciplines that suffer from only "feeling one part of the elephant" (Ng, 2008, p. 7). Overall, price-related research is dispersed across the disciplines of accounting (see reviews by Balakrishnan and Sivaramakrishnan, 2002; Lucas, 2003), economics (e.g. Hirshleifer et al., 2005; Nagle, 1984) and marketing (e.g. Ingenbleek, 2007; Monroe, 2011; Rao, 1984). There is also work done in psychology that has influenced price research. Most notable here is Kahneman's and Tversky's (1979) seminal research on decision making under risk. (For a more extensive and historical pricing review see: Diamantopoulos, 1991, this includes an elaboration and definition of price: p. 63-68.)

Besides the price-related research being done in these disciplines, there is an increasing body of work that takes a strategic perspective towards price (e.g. Anderson, 2009; Dutta et al., 2002; Dutta et al., 2003; Forman and Hunt, 2005; Piercy et al., 2010; Shapiro and Varian, 1999; Teece, 2010). Most notable here is the work of Dutta and his fellow researchers (Dutta et al., 2002; Dutta et al., 2003) that has shown how price is a strategic capability that is underpinned by resources such as information, skills and routines. Another more recent example is Piercy and his colleagues (Cravens and Piercy, 2009; Piercy et al., 2010) who explored the role of price in strategic positioning during economic decline and recovery. Largely, this kind of research takes a broader approach and argues that pricing as a source of competitive advantage has been neglected, and that this strategic aspect of pricing should be explored further (this notion is further elaborated on in the discussion section). This paper addresses this gap by developing the SBIFT model that can aid organisations in analysing strategic pricing.

\subsection{Pricing strategies and practises}

In practice, pricing is usually more complex than merely basing price on cost information (Monroe, 2003). Indeed, many factors influence successful pricing. Cost information is only the starting point that specifies the price floor (Shipley and Jobber, 2001) and additional information is needed for managers to set an appropriate price on their offerings. Here, information about the customers' perceived value is of central concern. To determine this is, however, difficult. For example, Zeithaml's (1988) seminal work shows that value is a combination of what a customer wishes for (consciously or subconsciously), perceived quality, and the perceived extrinsic (e.g. 
price and brand name) and intrinsic attributes (e.g. flavour, colour and texture) of the offering. There is in addition a temporal dimension (Shipley, 1981) in customers' perceived value that makes price determination even more difficult. Besides customer-related information, there is a more long-term and strategic aspect that managers need to consider in pricing decisions (Dutta et al., 2003; Piercy et al., 2010). In fact, the way an organisation sets its prices has the potential to change customer behaviour and have a long-lasting impact on customer relationships (Gourville and Soman, 2002).

Lately, information technology (IT) has made pricing practices even more multifaceted (Dixit et al., 2008; Jonason, 2001; Kung et al., 2002). Not only is the pace of technological development rapid (as predicted already by Turing, 1950), with the consequence that cost and physical size of IT capacity keep falling. But IT also has the potential to make traditional costing-based pricing principles obsolete, especially for digital products such as software and music and video content. With a copy cost that approaches zero, all the production cost is in the form of initial investment. Thus there is no marginal cost of production to serve as a floor for pricing (Shapiro and Varian, 1999). This can be used to provide versions of the offering for free to increase awareness of the product, capture market share and provide a better basis for a customer's decision to pay for premium versions, as explored for example by Anderson (2009). There are also enabling aspects, affecting relations and market functions. Dixit et al. (2008) show that IT and the Internet have prompted significant changes in companies' pricing strategies through increased information availability and enhanced reach and interactivity between actors in a market. As a result, IT has opened up for a vast array of price strategies and there is nowadays a significant increase in varieties of price models and concepts (Jonason, 2001), such as versioning (Bhargava and Choudhary, 2008; Shapiro and Varian, 1999), automated pricing (Ariely et al., 2004; Iyer and Pazgal, 2003), freemium (Anderson, 2009; Wilson, 2006), and bundles (Bakos and Brynjolfsson, 1999; Janiszewski and Cunha Jr, 2004)—just to name a few.

Indeed, pricing is increasingly complex (Dutta et al., 2002) because it is influenced by a myriad of factors (Diamantopoulos, 1991; Ingenbleek, 2007) and because there are numerous price models and strategies (Dixit et al., 2008). Maybe this is also why some researchers claim that managers often have an unstructured approach to pricing (Dixit et al., 2008; Hinterhuber, 2004; Marn et al., 2004; Shipley and Jobber, 2001). For example, Piercy et al. (2010) argue that managers' approach towards pricing is often piecemeal and patchy and based on short-term tactics instead of longterm strategic thinking. Given such a backdrop of the complexity of pricing, there is a need to make pricing less messy and a need for a model that can make sense out of the repertoire of different price models that a company can choose to deploy $(\mathrm{Ng}, 2010)$.

\section{Methodology}

\subsection{Research approach}

This article is a product of a collaborative research project with the telecom company Ericsson. ${ }^{1}$ Ericsson is particularly interesting in the study of price models because the speed of development in the telecom industry forces them to continuously rethink their price models. As they have a differentiated portfolio both in terms of customers and offerings, they encounter business situations where very different price models may be appropriate.

Collaborative research enables creative interaction between scholars and practitioners with different views and approaches that can contribute to both theory and practice (Ahlström et al., 2007; Fendt and Kaminska-Labbé, 2011; Parvinen et al., 2010). For example, the seminal research of Argyris, Schein and Freud is based on the underlying principles of collaborative research (Pasmore et al., 2008b; Werr and Greiner, 2008). Most collaborative research approaches (Shani 
et al., 2004) share the notion of collective inquiry where scholars and practitioners jointly seek "answers to questions of mutual interest through dialogue, experimentation, the review of knowledge, or other means" (Pasmore et al., 2008b, p. 12). In such a process, they often co-produce knowledge by both formulating the research question together and jointly participate in the research process (Van de Ven, 2007). The purpose of collaborative research is not to primarily perform research for practice but instead with practice, the ultimate goal being to advance knowledge (Van De Ven and Johnson, 2006).

\subsection{Research process and data collection}

The collaborative research with Ericsson was undertaken between September 2009 and September 2011 and was initiated by assembling a research team consisting of two practitioners and five researchers (for earlier work within the research project see e.g. Westelius et al., 2010). Having both "insiders" (i.e. Ericsson employees with pricing experience) and "outsiders" (i.e. researchers) was intentional since such a constellation has been reported to have significant advantages for high-quality collaborative research (due to its potential to integrate diverse perspectives, Amabile et al., 2001; Bartunek and Louis, 1996). Subsequently the research team jointly defined the research question and then the data collection began that consisted of interviews and focus groups. The interviewees and focus group participants were Ericsson employees and were identified by referral sampling. Their common feature was that they had significant experience from development and deployment of price models. They came from different levels of the organisation: e.g. corporate managers dealing with strategic issues (including pricing), pricing managers responsible for developing price models, and commercial managers working with implementation of price models.

In total 31 interviews were conducted with 39 participants from Ericsson. (During eight of the interviews there were two respondents). The interviews lasted approximately one hour and they were open-ended and inductive in nature. The main question posed was: in your line of work, what are the most important issues regarding pricing and pricing processes and have you encountered any unconventional price models or practices?. The aim was to increase the understanding of empirically-driven issues and practices connected to pricing and to obtain data that were used in the concurrent focus groups.

Secondly, 33 focus group sessions were performed with approximately 35 participants from Ericsson, totalling about 90 hours. Some, but not all, of the participants also participated in the interviews. Excluding project group members, Ericsson participation was four participants on average. During the focus group sessions, the basic empirical aspects of the dimensions of the SBIFT model were co-created, developed and validated, which included the exploration of alternative interpretations. For example, the participants discussed the concept of rental or payper-use as alternatives to traditional selling, with a perpetual transferral of rights. This formed the basis for the dimension "temporal" (see below) that was developed during the data analysis.

\subsection{Data analysis}

The data analysis consisted of three phases with attentiveness to both similarities and dissimilarities in theory and data (inspired by the guidelines of: Glaser and Strauss, 1967; Miles and Huberman, 1984). Data analysis was executed concurrently with data collection and was performed with a cyclic trajectory until saturation had been reached.

In the first phase, the data was open-coded into descriptive categories (empirical data from outside Ericsson was also included, see the second reliability and validation strategy below). The coding was inductive in nature and focused on the key themes that recurred within and across the different data sets. In other words, it consisted of patterns of what the participants believed to be 
issues of concern when trying to price their offerings appropriately and examples of unconventional strategic pricing practices. For example, one recurring issue was that competitors in the global environment could obtain price information about similar offerings (due to transparency of the market). Ericsson's negotiating power in pricing was therefore often eroded because the offering and its price model were compared with competitors. Consequently, Ericsson had a significant incentive to re-configure the price model by, for example, pricing a package of services instead of individual attributes of the offering.

The second phase was more deductive and consisted of a literature review (of which the most significant sources are displayed in the theoretical and discussion sections). This included research not only specifically about pricing (e.g. Jonason, 2001; Monroe, 2003) but also covering a broader area (e.g., price models, business models and strategy: Baden-Fuller and Morgan, 2010; Teece, 2010; pricing and the digital economy: Peitz and Illing, 2006). Overall, this phase facilitated the extension of the participants' novel and undeveloped ideas from interviews and focus groups.

The third and final phase entailed a re-coding of the data. The understanding gained from the open coding, concurrent data collection, and theory insights from phase two influenced this third phase. This re-coding procedure was conceptual, and less broad and inductive compared to the open coding. As a result, the SBIFT model presented in this paper was created.

The data analysis process can be illustrated by the following example: during the first phase, we identified patterns of unconventional pricing practices when Ericsson's customers increasingly determine the price in some contracts, by design or by insufficiently specified price computation conditions. In the second phase, we connected this key-theme with research on participating pricing (e.g. Kim et al., 2009)—particularly Munthe's (1930) and Anderson's (2009) ideas about the desirability in some cases of letting customers pay as much or as little as they want. In the final phase this was identified as a step in the third dimension and labelled "Pay-what-you-want" (see below).

\subsection{Strategies for reliability and validity}

The key product of our research is the SBIFT model to be depicted in Figure 1 below. Its five dimensions were selected and labelled through the long and arduous process described above, and can obviously not—as any model—be "validated" in any absolute definite sense, in particular as we do not claim that they are exhaustive. The dimensions and subcategories along each dimension have stabilised over the course of our collaborative research project, and no further suggested changes or additions have surfaced during the last six months of the research project. Overall, we have used a fourfold strategy for reliability and validity (following the recommendations stipulated by: Johannisson et al., 2008; Shani et al., 2008; Van de Ven, 2007).

Firstly, the members of the research team had different backgrounds and affiliations, and such heterogeneous composition is considered to have significant advantages for collaborative research (Amabile et al., 2001; Bartunek and Louis, 1996). For example — and in addition to the insider/outsider approach — team members were connected to four different academic institutions and held expertise within the areas of accounting, strategy, management control, information systems and organisational change.

Secondly, rigorous collaborative research should strive for reliability across settings (Lindhult, 2008; Pasmore et al., 2008a). Therefore, nine additional interviews were performed with twelve participants (during three interviews there were two participants) from the industries of management consulting, law, graphics and printing, banking, university, railroads, and gaming 
(this empirical data was also included in the data analyses). Here, the basic parts of the SBIFT model were further developed and applied to different industry types of products and services. The aim was to increase both the model's robustness and its applicability and generalisation to different industries and contexts. The interviews were structured in the same way as the data collection in Ericsson and were divided into two parts. The first was open-ended and focused on the same main question that was posed during the interviews with Ericsson employees. In the second part, the SBIFT model was presented and discussed and then assessed by trying to apply it to the respective organisation.

Thirdly, one common feature of high-quality collaborative research is the use of advisory boards and review panels (Van de Ven, 2007). Accordingly, a review panel was set up that was composed of six managers from Ericsson with experience from pricing, and this group met the research team on a regular basis during the whole research project. The purpose of these meetings was to monitor and critically review the progress and to evaluate emerging ideas of the research project (e.g. assess the extent to which the dimension of price influence is a relevant dimension of price models). An advisory board was also used that comprised eight Ericsson representatives and had recurrent meetings with the research team. The purpose of the advisory board was to give advice on different aspects of the emerging model based on experience from different parts of the Ericsson Group regarding designing and implementing price models.

Fourthly and finally, rigorous and high-quality collaborative research is often assessed by peers and tested on students for its teachability and transferability to students (Lindhult, 2008; Pasmore et al., 2008a). Thus, the SBIFT model was put under scrutiny by colleagues from two different research communities and tested in courses at three universities.

\section{Results}

\subsection{The SBIFT model}

Pricing is vital when strategies are developed. At a conceptual level, the links between the strategy, price modelling and the competitive arena are rather straightforward. The organisation should develop a strategy that fits well with the competitive arena (i.e. opportunities and threats) and the resources of the firm (i.e. strength and weaknesses; Learned et al., 1969). The competitive arena affects what type of strategy is suitable and the organisation affects its environment (cf. e.g. Hrebiniak et al., 1989, p. 5). In this constantly ongoing adjustment process, how prices and price conditions are expressed is probably one of the most important instruments available to top management. There are of course other instruments, such as product, place and promotion in the marketing mix, but compared with the other elements in the marketing mix price is the only element that often does not necessitate significant expenditure and has more immediate effects (Diamantopoulos and Mathews, 1995; Dutta et al., 2003; Forman and Hunt, 2005; Rao, 1984).

However, at the level of practice, pricing is much more difficult. One reason is the lack of a tool for communicating about alternative price models that could help managers and scholars to link the world of strategies to the world of business offerings. This void in the literature is addressed in this article by developing the SBIFT model (an acronym for the five dimensions Scope, Base, Influence, Formula and Temporal rights) for strategic pricing, displayed in Figure 1. This article defines price models as systems of price-related aspects of the agreement between a seller and a buyer. Any agreement between buyer and seller will use one particular price model, and we propose that such models can be described through five important dimensions according to which such an agreement can vary. These dimensions are, directly or indirectly, present in any agreement between seller and buyer. Depending on the specific price model and situation, some dimension(s) may be dominant (see section 4.2). The dimensions are listed without any order of 
priority or causal relationship. Together, the five dimensions constitute an overarching model for price models, which also can be seen as a generic model for describing particular price models through the specification of their "positions" on each of the dimensions. The SBIFT model is not all-inclusive and should be seen as a sensitising device that can help to explore and utilize the repertoire of different possible price models that an organisation may deploy for its products and services. An organisation (or researcher) can use the SBIFT model by plotting an offering according to the five dimensions and identify an industry standard (see examples in Figure 2, 3, and 4). By doing so, an organisation can analyse competitors' and their own pricing strategy and determine how they can differentiate by price and where to diverge from the industry standard.

Scope

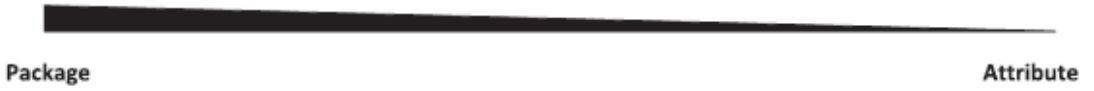

Base

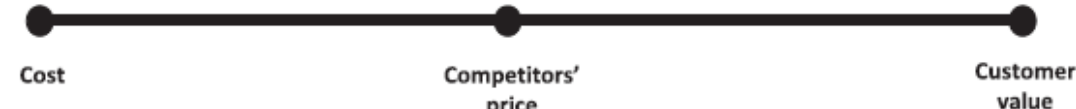

Influence

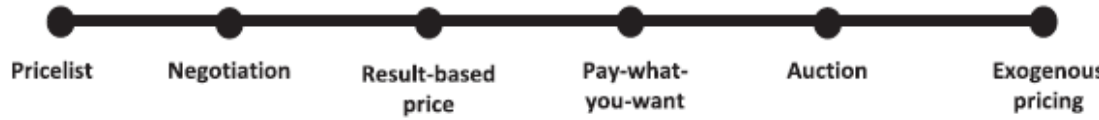

Formula

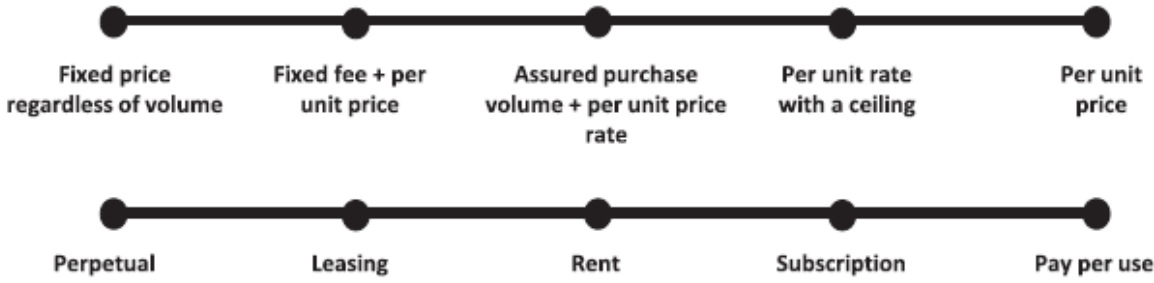

Temporal rights

Figure 1 The SBIFT model.

Figure 1: The SBIFT model

\subsubsection{Dimension one: Scope}

The first dimension refers to the granularity of the offer. At one end of the spectrum, a complete Package of products and services is the object that is priced. At the other end, each Attribute or lowest-level unit of the offer is priced individually and can often be bought or not bought individually. For example, Cunard Cruise Line offers a complete package in their pricing of a seven-day cruise in Europe. The customers pay for a bundle of products and services (e.g. travelling, accommodation, food, and entertainment) irrespective of if they choose to make use of the parts of the bundle or not. Conversely, Ryanair splits up their offering into different products, such as flight, priority in boarding, luggage allowance, beverage, car rental, travel, and insurance. In this way, the customers can, by themselves, choose among the attributes of the offering and thereby influence the price by deciding what to include.

\subsubsection{Dimension two: Base}

The point to consider in the second dimension is what type of information base that dominates the pricing decisions. The most classical alternative here is information about the Cost of developing, producing, distributing and selling the products and services. Based on such information, the company can determine the price floor. According to our discussions in the focus groups at Ericsson and our interviews with people in other companies and industries, cost 
is also viewed as a legitimate basis for pricing by both sellers and buyers. Sellers find it easy to defend a price set on cost, and buyers view cost-based arguments as reasonable; the profit margin can be a matter of negotiation, but claiming that products should be sold below cost does typically not appear as tenable. For some organisations, costing information is crucial, since they operate within a regulated industry in which price may not exceed cost including a stipulated cost of capital. For example, the price levels of municipal services such as water and sewage are often set according to such principles and regulations (Malmer, 1996). In strategic management accounting, it is suggested that competitor's costs should also be part of the base for pricing decisions (Lord, 2007). However, such information can be difficult to obtain.

Basing price level only on cost information is often suggested as not advisable (Hinterhuber, 2004; Ingenbleek, 2007; Shipley and Jobber, 2001). In setting an appropriate price level, an alternative starting point is Competitors' price for comparable products and services. Consulting is an example of an industry which relies heavily on such information in their pricing decisions. In telecom and other industries with high development costs and low reproduction costs, costing becomes heavily influenced by estimates of potential sales volumes. Competitors' pricing then tend to take precedence over other bases for pricing.

Last, but not least important, is information about Customer value that assists in the determination of a price ceiling. This is the starting point preferred in the marketing literature, and an increasing body of research underlines the importance of a customer-value approach (Ingenbleek, 2007). Rather than production cost or market price, customer value takes what the customer perceives as valuable as its starting point. Setting the right price is then seen as finding the proper balance between customers' perceptions of what they obtain and what they sacrifice in order to acquire or use the offering. Cost, competitors' prices and customer value could serve jointly as bases for setting prices, but typically, one or the other dominates in the particular case. And although customer value may appear appealing from a theoretical strategic or marketing perspective, it is difficult to determine in practice, while costs and competitors' prices tend to still figure prominently in price determination and price negotiations. In our discussions with practitioners in the research project, customer value is viewed as an ideal base for pricing, but difficult to use in practice. Purchasers' cost focus, competitors' pricing and the own sales force's conception of legitimate and defendable prices tend to quickly erode the possibilities for customer value as a dominant price base, but in novel offers and unique add-on features to established products, customer value finds its application even in practice.

\subsubsection{Dimension three: Influence}

This dimension of the SBIFT model is concerned with the extent to which either the seller or the buyer has the ability to influence the price. It is often connected to the situation of a given market and the power play of negotiation between seller and buyer. In the most extreme situation at one end, the seller has the ability to set the price according to their own criteria and communicates it to the buyers using a Pricelist. The customer's ability to influence the process is limited to whether to buy the offering at the list price, to refrain from buying altogether or to purchase the product or service from another seller that offers a more attractive pricelist. In the next type in the SBIFT model, the power balance between buyer and seller is more even. Therefore, the price is set based on Negotiation. Here too, the starting point is often a pricelist but the customer has enough buying power to challenge the pricelist and invoke negotiations. For example, one participant in the focus groups noted that when HP sells computer equipment to Ericsson in large contracts, they begin with a price list but the final price is set in negotiation. The negotiation can also start with a (too low) price offer from a potential customer, followed by attempts from the seller to get the buyer to offer more favourable conditions. 
The next type along the influence dimension is based on some observable outcome of the use of the product or service and is here termed Result-based price. Here, the price is set in accordance with the result of the use. Normally, this will be more within the control of the buyer than of the seller, and it also necessitates some agreed-on mechanism for determining the result - e.g. monitoring use. However, sometimes the seller may be more convinced of a high rate of utilisation than the buyer, for instance when introducing new customer services.

An example of result-based pricing where this may have been the case, provided by a participant from Ericsson (but also noted by e.g. Schedler et al., 2004), is from the 1990s when the consultancy company Bearing Point developed a website for the state of Texas that was used to provide citizens with charged local government services such as driver's licence renewal, motor vehicle registration and occupational licenses. For example, a citizen could pay about $1 €$ for submitting their tax declaration online instead of driving several kilometres and queuing. The development of the website was free and instead, the company made their revenue based on the income from the charged services. BearingPoint received 90 percent of the gross revenue generated until its initial costs were recovered. Thereafter, the revenue was shared equally between BearingPoint and the state of Texas.

The fourth type on the influence dimension is when the pricing decision is delegated to the buyer, who determines and sets the price of the offering: Pay-what-you-want (also referred to as pay-as-you-wish). In this type of pricing, the organisation can recommend a price that the customer can choose to accept (Salisbury cathedral: "We expect a voluntary gift of no less than 50 p") or the customer can decide for her- or himself what the offer is worth. Axel Munthe, a high-society physician of European fame a hundred years ago, claimed that pay-what-you-thinkthis-was-worth was a highly successful pricing strategy when he used it among his patients (Munthe, 1930). A contemporary example of this type of pricing is the rock band Radiohead who released an album that fans could buy and download at a price that they determined themselves within a given period of time (and the attempt was apparently profitable; Kim et al., 2009).

The next step along this dimension is when both the provider and each individual customer relinquish the right to determine the price level altogether by letting an Auction determine the price. The buyer is unable to determine the price beforehand and the price is set in relation to what other buyers are willing to pay for the same product or service. The seller's ability to influence is limited to the extent that they may accept or decline the highest bid.

Finally, the other extreme of this dimension is Exogenous pricing, which means that circumstances beyond the influence of both the provider and the consumer determine the realised price level. This type of pricing is common in long-term contracts of complex products and services. One example of such pricing was provided by a participant: when Concordia Bus Group-the largest public transport group in the Nordic region-obtained a contract from a municipality to run the public transport, the price was linked to an index that was agreed during the price negotiations. The index formula contained various external components, such as the cost of oil, wages and GDP growth. During the contract period, which could be up to ten years, there was no opportunity to renegotiate the terms. A reference price was set at the beginning of the period and was then multiplied by the index to calculate the current price.

\subsubsection{Dimension four: Formula}

The fourth dimension of the SBIFT model is concerned with the formula used to connect price with volume. With a Fixed price regardless of volume, the seller is guaranteed an income even if the volume turns out to be low, but will not receive anything extra if the volume increases. At the other extreme, Per unit price, the buyer bears no risk if volume turns out to be low, but every extra 
unit comes at an extra cost. Some customers find certain formulas more attractive than other customers. For example, customers with high debt/equity ratio may find the price model with complete volume variability most attractive, because it will match income with costs. Someone with lower debt/equity ratio will be able to better bear a mismatch between income and cost, and is likely to prefer a formula where the upside of high volume will accrue to the customer. Telecom operators, like TeliaSonera and Vodafone, tend to base the prices of their subscriptions on variations along this dimension. Therefore, many of the illustrative examples in this section are provided from this industry.

To start with, located at the left of the axis, is Fixed price regardless of volume. As noted, this type refers to products and services that have a fixed and pre-determined price that is independent of consumed quantity. For example, some telecom operators offer subscriptions that allow subscribers to call as much as they want for a fixed monthly charge. Airlines offering annual passes is another example. Another illustrative example is fitness centres that often charge an annual price knowing that only a fraction of their customers will actually show up regularly.Fixed price regardless of volume is a low-risk alternative for a supplier whose costs are primarily not variable by volume.

Next on the axis is the type Fixed fee plus per unit rate. Here, the price has two components-a fixed fee plus a component that depends on the quantity actually delivered or used. For example, telephone subscriptions can have a monthly fee plus a rate for the number and length of calls. Another example is power companies who may charge a fixed fee for the ability to deliver electricity plus a rate per $\mathrm{kWh}$ delivered.

In the middle of the axis, Assured purchase volume plus per unit rate is located. The seller is guaranteed contracting for a certain volume of the offering, and will be paid a fixed amount regardless of whether that quantity is used or not, and the buyer will have to pay extra for every unit above that quantity. E.g. a telephone subscription can include 100 minutes and 5,000 texts, and a rate per minute and per text if the subscriber exceeds these quantities. Or a printer may offer a price for the first 10,000 copies plus a per unit price for additional copies.

The fourth type of pricing along this dimension is termed Per unit rate with a ceiling. This means that the buyer pays the per unit price up to a certain level, above which the seller no longer charges for additional units. The Stockholm city congestion charges are paid per entry or exit up to an amount of 60 SEK per day per car.

Lastly, at the far right of the axis is the type per unit price. For example, many lawyers and management consultants charge by the hour. With this price model, a second hour of legal or management consultant service will be priced the same as the first hour, regardless of if the quality of output from the second hour differs from the first hour, or there are economies of scale for the producer.

\subsubsection{Dimension five: Temporal rights}

The fifth and last dimension focuses on for how long customers have the right to use the offering. This is referred to as Temporal rights and as Figure 1 illustrates, the further we go to the right on the axis the shorter the time period is for the customer to use the product or service. In our discussions with practitioners, we have identified a number of types of temporal rights, and have arrived at the following five as subclasses along the dimension. At the left we find Perpetual, the classical type for goods. Here the customer has the temporal right to use the offering forever (at least theoretically). However, the customer may only use the version of the offering he or she has bought. After the purchase, the consumer will not have the right to any enhancements that 
the seller makes to the product. It is sold as is. For example, computer hardware components are typically acquired with perpetual ownership, but in practice, the economic life of such products is far shorter than their technical life.

The second type, Leasing, is a combination of a time-limited and a perpetual component; the customer buys the right to use an offering for a specified period of time, typically a number of years, and has the right to buy it for eternity at a predetermined price when the leasing period ends. Leasing is a common way for many organisations to pay for company cars.

The third type is when a customer Rents an offering for a specified period of time. Here, we use rent to signify that the customer temporarily buys the right to use the product or service (without any updates or changes during the rental period) but has to return it when the rental period is over. The fourth type, Subscription, is also a way of transferring the right to use a product or service for a specified period of time, but includes upgrades and enhancements made by the seller. To some extent, it thus includes content or functionality that does not yet exist at the start of the rental period. For instance, subscription is a common pricing strategy for software that gives the customer the right to use the current software and the right to receive future (modified) versions of the software for as long as the subscription period lasts.

Finally, at the right-hand side of the temporal dimension, Pay per use is situated. A classical form for selling services and increasingly popular for selling digital content, it means that the buyer pays for every occasion of using the product or service, e.g. a flight or a streamed film.

\subsection{Application of the SBIFT model}

To illustrate the SBIFT model and how it may be used, we present two cases based on public information and focus group discussions. ${ }^{2}$ The first case is Google AdWords, Google's main online advertising product. Google AdWords is the name under which Google sells ads that are displayed beside Internet search results generated by their popular search engine (see Figure 2). The second case is Ryanair, an Irish low-fare airline with a low-cost, high-utilisation strategy (see Figure 3). These case studies were chosen because they have well-known offerings with unconventional pricing, and are well suited for our aim to provide examples of pricing analyses and to explain the rationale behind the framework in an unpretentious way. 


$$
\text { X = Google AdWords } \quad \text { = Industry standard of comparable offerings }
$$

Scope

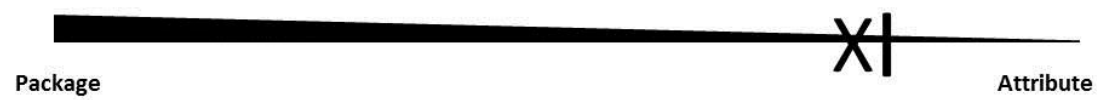

Base

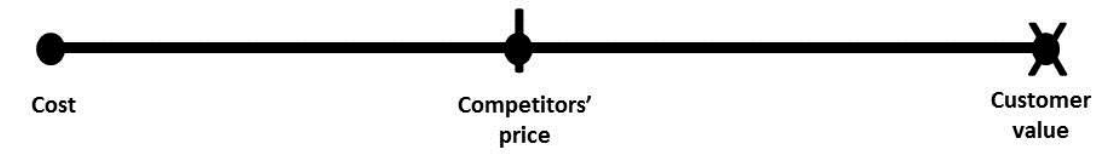

Influence

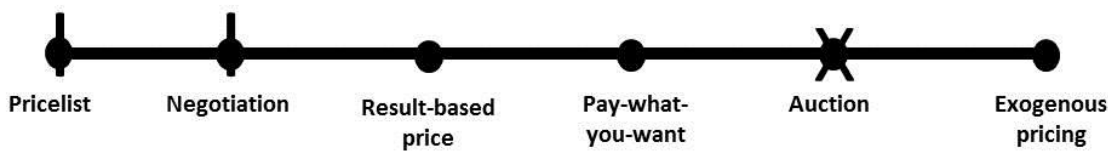

Formula

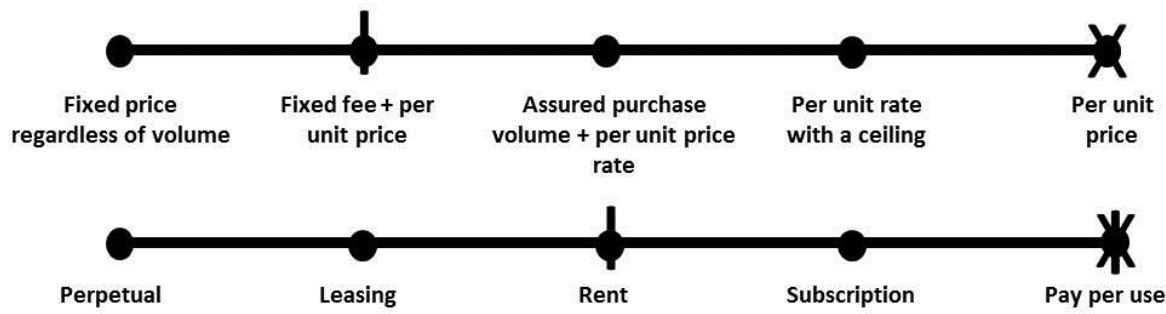

Figure 2: The SBIFT model applied to Google AdWords

Along the first dimension, Scope, Google AdWords is located close to the far right of the scale. This is because what is being sold is the display of single clickable ads beside relevant Internet search results, and statistics of use that allow the customer to evaluate and modify ads and willingness to pay. In the second dimension, price is set based on Customer value because the price is connected to customers' evaluation and bidding on keywords. Each buyer determines the upper limit for what they are willing to pay, and the more bids and the higher the competing bids for a word, the higher the price of the ad space that is connected to the keyword. According to the third dimension, neither Google AdWords nor the individual customer has the determining influence over the price-level, since the price is determined by automated Auctions every time Google generates a search result. The ads are displayed in accordance with the order they ended up in the auction, at individual prices. Along the fourth dimension, Google AdWords has chosen a formula based strictly on Per unit price. The customer is charged per click on the displayed ad, not, for example, on the length of the advertising period or for a minimum number of displays. Regarding Temporal rights, the last dimension, Google AdWords is placed in the category of Pay per use because the client buys the advertising space momentarily each time the result of a search question is displayed and pays only for the single occasions when the Google user actually "uses" the product by clicking on the Internet link located in the search result.

Google AdWords' price model is conventional in the fifth dimension, Temporal rights, and the first dimension, Scope. It is common that companies in the online advertisement business charge per use for click-through (although charging for display for a certain period of time-rental—is also sometimes employed), and for individual ads (perhaps even without advanced use statistics, and this is why the industry standard is located a little bit more to the right in dimension one). 
It is rather in the second, third, and fourth dimensions that Google AdWords diverges from the industry standard and has managed to differentiate by price. There is an overall ambition within the advertisement business to strive for basing the price on Customer value, but the majority of actors are in most cases limited to instead use information about Competitors' pricing. Enabled by its technology, Google AdWords has succeeded in basing the price on Customer value to a much larger extent than competitors. Regarding Influence, Google does not use its size to force a price list on the customers - a common practice in the industry, where only the large buyers can hope to Negotiate a price. Instead of either of those practices, Google uses its technology and the volume of advertising business to differentiate itself from its competitors by employing a dynamic Auction, per search. Finally, its Formula is also unconventional, again relying on Google's size and technology. The service is completely computerised and customeradministered. There is thus no need for a fixed fee as part of the Formula (employed by many competitors with less automated services). Also, Google's size and AdWords' no-touch routines allow Google to accept all customers with no lower limit. It is possible to be a customer who pays for a single click-through or none in a month. However, Google relies on the self-interest of the customers in increasing their success rates, and thus their payments to Google. To support such development, Google AdWords offers the use of statistics and advice on how to improve advertising success.

Google's price differentiation in the case of AdWords, enabled by efficient self-service technical solutions, allows them to profitably cater to mass markets where new customers can experiment at very little risk and cost. This differentiation mainly builds on the dimension Base and Influence, and to some extent on Formula. 


\subsubsection{Ryanair}

X = Ryanair

$=$ Industry standard of comparable offerings

Scope

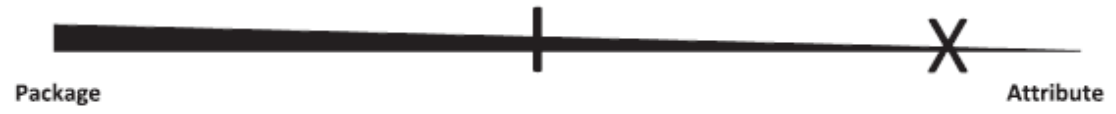

Base

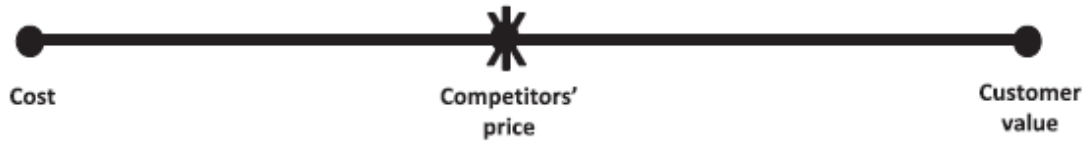

Influence

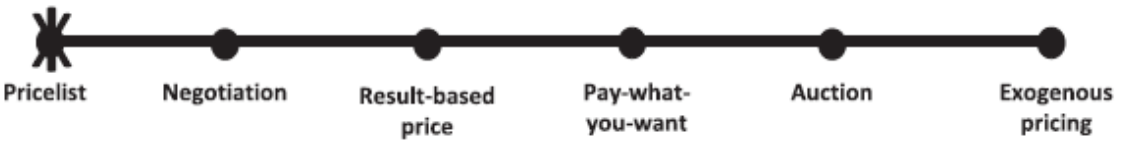

Formula

\section{Temporal rights}

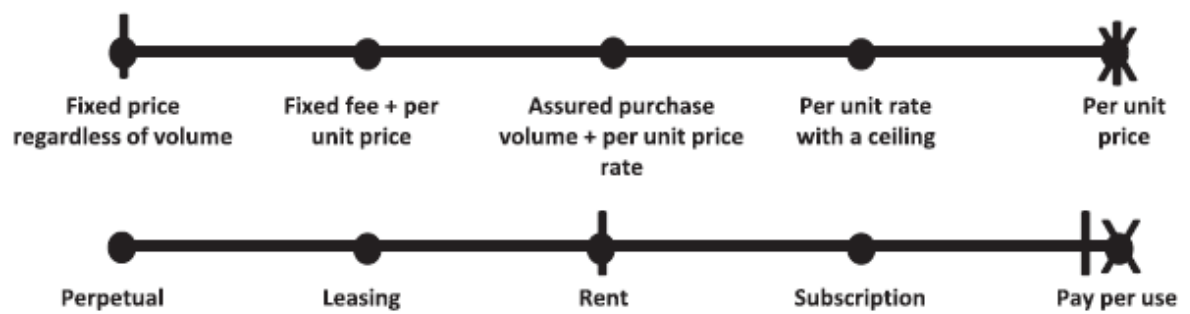

Figure 3: The SBIFT model applied to Ryanair

To begin with, and as noted earlier, Ryanair has chosen to offer each component of their offer separately. The customer can choose from a wide variety of components (luggage allowance, food, beverage, insurance, rental cars, etc.) to compose their customised package. Along the second dimension, Ryanair bases their pricing decisions primarily on information from Competitors' pricing, making the salient components competitively priced. Non-essential parts of the offer, such as priority boarding, luggage allowance and food on board, can then be priced according to what a sufficient number of locked-in customers can accept to pay. The customers have no influence over the price of any part of the offer; along the third dimension Ryanair offers a non-negotiable pricelist (where prices may change over time according to availability-based yield management practices). Ryanair's approach in the fourth dimension is Per unit price. They have a strict point-to-point policy and do not even offer connecting flights as packages, nor do they offer bonus points. Even more remote would be the idea of offering annual passes. Along the last dimension, the customer pays for the transportation from location $\mathrm{A}$ to location $\mathrm{B}$ on a strict Pay per use basis. The customer has to pay separately for every occasion when he or she decides to travel to a destination. No fixed-period options are available.

Along dimensions two and three, Ryanair's pricing conforms to industry standard: prices are set with a great deal of attention to Competitors' prices and airlines offer non-negotiable Price lists. Along the other three dimensions, conformance varies. Along the Formula dimension, the Ryanair choice Price per unit (flight) is normal, although many airlines also offer fixed price regardless of volume alternatives, such as period passes or flight packages ("round-the-world up to 62,000 kilometres or based on the number of continents that you visit"). Regarding Temporal rights, Ryanair again takes an extreme position by adhering strictly to a point-to-point policy. Other airlines typically offer travel from start to end destination, assuming responsibility for connections, thus offering somewhat longer durations (of Temporal rights). And again, period passes that can be viewed as a type of fixed price regardless of volume and can therefore also be 
viewed as a type of rental: use the service (flights) for a year (or three weeks) at a predetermined price.

The most prominent differentiation in Ryanair's pricing strategy lies in the first dimension. By offering choices of attributes at a high granularity instead of an invariable bundle Ryanair affords the customer with the possibility to compose a customised package from standard components and thus affect the total price paid. This is by no means a Negotiation-Ryanair has determined which options to offer and the prices at which they are offered. Thus, the customers' customisation possibilities build on a take-it-or-leave-it basis, not on Negotiation. Ryanair's unbundling approach is one important part of its low-fare image and its low-cost, high-utilisation strategy.

Altogether, the case studies illustrate how price models can be analysed by using the five dimensions of our SBIFT model. They also show that depending on the business a company is in, as well as the standards of industry price models, the importance of certain dimensions in the SBIFT model may differ. The organisations that manage to differentiate by price seem to do so by strongly diverging only along a few dimensions.

\section{Discussion}

\subsection{Theoretical discussion}

The SBIFT model captures the different aspects of what the participants in the collaborative workshops and the interviewees in other industries believed was of central concern when they try to set an appropriate price for their products and services. As described in the section on collaborative research, we have used it extensively and it has encouraged new ideas on price models and provided structure to participants' observations of emerging price strategies in the markets with which they were familiar. Besides this practical importance, there are also a number of theoretical discussions, as well as contemporary pricing debates, which can be traced to the different dimensions. In this section, this will be elaborated on.

The first dimension, scope, is related to the strategic question of what should be considered to be the core offering, and what should be considered peripheral. Normann and Ramírez (1993) argued that in practice, a core product is often surrounded by offerings that are perceived as valuable by the customer, but that a seller may be less aware of. In this respect, an organisation can change their pricing (or even make alterations to the offering) if they can identify the valuecreating offerings that surround their product or service. Similar ideas also underlie the concept of bundling of information goods (Bakos and Brynjolfsson, 1999). Considering that the copy cost of information goods is close to zero, bundling more peripheral products with a more central one can create a package that a customer that would not have bought the peripheral products separately would still appreciate and pay more for than for the core product alone. There often are economies of scope in both production and use. But, as the Ryanair example demonstrates, unbundling can also provide competitive advantages. Ryanair has developed a cost-efficient way of providing the unbundled offer, it sets them apart from competitors who provide more bundled offers and some customers appreciate the customisation possibilities of the unbundled offer.

Regarding the second dimension, although currently overshadowed in the literature by Customer value as a strategically desirable basis for setting prices, Competitors' prices appear to have a strong hold in practice. Out of the examples discussed in the research project, only Google AdWords appears to succeed in basing prices on Customer value to a large extent. One reason may be that it is difficult for a seller to determine Customer value. Google AdWords' mass of customers and transactions affords the company with a possibility to employ automated and 
dynamic auctions that would be unfeasible for most other companies. In addition, Google's economies of scale allow the company to offer attractive services at a competitive price. For less dominant players, the possibility to pursue Customer value is linked to their ability to offer distinctive features that customers value highly enough to pay a premium (i.e. upscale differentiation) or strip versions to offer more basic functionality at an attractive discount (downscale differentiation). In practice, it will in such situations often be difficult to determine customers' willingness to pay, so Customer value remains an abstract idea about how high a premium is possible, or how large a discount is necessary. It is a game situation, just as in classical theories for oligopoly or monopolistic competition.

In telecom markets, for example, aggressive operators attempt to buy market share (or hurt incumbents) by offering products at highly competitive prices. Mobile broadband in Sweden is such an example. When one actor starts offering mobile broadband at 200 SEK or $€ 20$ per month, there is little room left for other players to try to explore and capture a Customer value that exceeds the established market price without offering what customers perceive as superior quality or attractive extra features. In some markets, major brands seem able to command a premium for a premium package (like Orange in France ${ }^{3}$ ). Considering the appearance of a markup in comparison to the lower-quality offers, and the potential wide variation in actual customer value experienced by different customers, there is little to suggest that the premium price is based on an advanced estimate of customer value rather than on a schematic comparison of offers.

Better coverage and achieved speeds twice those of the low-price competitors could warrant a price twice theirs. Knowledge of competitors' prices and "feeling for the market", in a consumer market possibly supported by some experimentation, serves as a basis for determining prices. This might explain the frequent reference to Competitors' prices in our discussions with managers, rather than systematic studies of Customer value or willingness to pay. Price elasticity for various possible features remains a hypothetical construct, at best.

The third dimension includes a range of price models that have been advocated in connection with advances in information technology and the rise of the Internet. Some researchers claim that because of IT development in general, and the Internet in particular, there is an increase of information availability, enhanced reach between seller and buyer, and expanding interactivity that altogether has amounted to a shift in the determining influence from seller to buyer (Dixit et al., 2008). The research interest for such IT-enabled alteration of price influence is increasing, exemplified by, for example, internet auctions (Heyman et al., 2004), pay-what-you-want (Kim et al., 2009), and price signalling (Biswas and Biswas, 2004). How a firms' profits are influenced by such a shift of price influence has been debated (Anderson, 2009; Peitz and Illing, 2006), with some researchers suggesting that price models such as pay-what-you-want (that enhance the influence of the buyer) may indeed increase sellers' revenues (Kim et al., 2009). Some small actors actually have started using pay-what-you-want models or modified auctions as their main pricedetermination alternatives (e.g. HumbleBundle.com and IndieRoyale.com). However, the success of price-list-based actors (e.g., Ryanair) indicates that the influence over price determination is not uniformly moved towards customers.

Formula, the fourth dimension, focuses on the variables to which price is linked and how. It is not uncommon that price is contingent on variables that are unknown at contract time, such as future demand. This makes a business deal contain an element of insurance, as buyer or seller assumes the risk caused by future developments or discoveries about for instance technological feasibility. Depending on their expectations, different formulas will seem advantageous to them. When a variable is external to seller and buyer (cf. our third dimension of pricing), differing expectations may lead both parties to find a certain agreement highly attractive, because of their divergent views of the future. For instance, if the seller expects a higher value of the variable than 
the buyer, then the seller may find it attractive to link price to this variable. In doing so, the seller expects a higher price, while the buyer makes the opposite prediction. The situation is somewhat different when price is linked instead to a variable which affects only one of the parties. For instance, price may be conditional on the price development for some important ingredient which the seller uses to manufacture its offering, or the price may be expressed as a certain sum per user in the buying organisation. In both cases, risk is affected: in the first case, the seller is guaranteed compensation for extra costs, in the second, the buyer may find it acceptable to pay per user as the buyer expects additional revenues from each user. Both parties may make different forecasts about future consequences from the formula. Divergent expectations and an appropriate price formula may facilitate reaching an agreement, as both parties expect to gain. Divergent expectations may also make it more difficult, as when a buyer with high bargaining power attempts to make the seller bear all the risk arising from uncertainty about the future. A canny choice of variables, and an open discussion about differences in expectations, may sometimes alleviate such problems. Overall, these risk problems connected to the third and fourth dimensions underline the importance of a careful selection of variables, forecasts, monitoring systems and perceptions of fairness and acceptable effects on future earnings.

The fifth and last dimension is, for example, relevant to the on-going debate about the pricing of computer systems. The conventional way of getting a computer system is to buy or lease hardware and buy software, with or without subscription for updates. With the rise of outsourcing, fixed-term rental or subscription to the system provided as a service by the outsourcing company has become a popular alternative. Now, cloud computing allows companies to take yet a step in the direction of infrastructure as a service and software as a service, available via the Internet, and priced on a per use basis (Mathew and Nair, 2010; Susarla et al., 2009). In other words, the pricing of the product changes from the left (i.e. Perpetuity) to the middle (i.e. Rent or Subscription) and perhaps onwards towards Pay per use at the right of the dimension, in a way changing the nature of the product.

\subsection{Contribution}

Besides contributing to these different contemporary theoretical discussions in the field of pricing, there are three additional theoretical contributions of this article. Firstly, as the empirical applications of our model demonstrate, as well as the above theoretical discussions, this paper shows how pricing and price models are in fact connected to a broad range of explicit and implicit features. By doing so, this paper contributes by ensuring that researchers and managers avoid to commonly only feel "one part of the elephant" (Ng, 2008, p. 7) when they deal with the issues of pricing. (Such a perspective of the field of pricing is also supported by e.g. Diamantopoulos and Mathews, 1995; Ingenbleek, 2007; Piercy et al., 2010.)

Secondly, most pricing research is concerned with issues connected to marketing, accounting and economics (Diamantopoulos and Mathews, 1995; Ingenbleek, 2007) and the strategic aspects of pricing are often neglected (Dutta et al., 2003; Hinterhuber, 2004; Nagle and Hogan, 2006; Piercy et al., 2010). To prove this notion of lack of a strategic focus, you can perform a quick experiment by picking up a highly-cited book in strategy and look for pages that address the issue of pricing. Most likely, and at best, you will find very few pages which focus specifically on strategic pricing. For example, out of the 525 pages (excluding cases) of Johnson's, Whittington's and Scholes' (2011) popular textbook Exploring Strategy only 18 pages address issues of pricing (mostly being loosely scattered). Mintzberg excludes any larger reference to price or pricing in his book Tracking Strategies (2007). One significant exception is Porter's Competitive Advantage (1985), but still issues of pricing are spread out across 24 pages out of 536. The research done on pricing within marketing, accounting and microeconomics is commendable work. However, this paper suggests that we can extend the dispersed work being done in these areas and bring it up to 
a more aggregated level and incorporate it as one important part of the corporate strategy of a firm. Our model is one step forward in such a direction.

Thirdly, there is little, if any, research that actually tries to theorise and discuss the concept of price models. Indeed, price models are often taken for granted, are used in many different ways by researchers, and are often treated monolithically. For example, the majority of pricing research lacks a clear definition and avoids in-depth theorising. This paper suggests that a price model is more than just a representation of, for example, customers' willingness to pay, cost-plus formula, or the optimum level between the price floor and ceiling. Instead, price models are dynamic instruments constituted by a collection of implicit price-related aspects of current and future agreements between a seller and a buyer. In fact, we propose that price models are similar to strategy scholars Baden-Fuller and Morgan's analogous notion of the connection between business models and recipes: "The idea of the recipe suggests how the chef, within broad constraints of the principles of cooking and the kind of dish chosen, may create variations and innovations. If business models [in this case price models] play the same role, they too are not open ended but constrained, and involve ingredients that must be arranged and combined according to the recipe (i.e., to some generic business model), but yet have many possibilities for innovation." (Baden-Fuller and Morgan, 2010, p. 166). The SBIFT model for strategic pricing provides some, but by no means all, the ingredients that may be used in the making of a "dish". And such a perspective (or approach) re-enforces the strategic aspect of pricing.

Regarding the application of the model, the results indicate that finding one ideal price configuration based on the five dimensions of the model that would be successful in different industries is highly unlikely. Price models should rather be seen as tools for differentiating offerings from those of competitors, and thereby targeting specific customer needs. Appropriate selection and deployment of price models is thus subject to contingencies of the market in which the product and service is offered. A price model should be adapted to the specific situation. The systematic overview provided by the SBIFT model can facilitate such analyses. Overall, the application of the model to the two cases suggests that companies that manage to differentiate by price tend to do so by diverging from the common practice along a few selected dimensions, not along all dimensions.

\section{Managerial implications, limitations and future research}

From a managerial point of view, the SBIFT model can be used both descriptively and prescriptively. It can aid managers' strategic discussions by facilitating comparison of current patterns of pricing within an industry and by indicating in what ways they can differentiate future offerings from their competitors'. The model can help detect combinations of pricing that have not yet been offered and that have the potential to increase revenue and re-define products and services. In doing so, it aids in the exploration of strategic pricing.

For example, the model forces managers to consider questions like: What level of bundling or unbundling would offer the best prospects? (Dimension 1: Scope); What bases for pricing can we access, do we trust, and are we willing and able to base our price levels on? (Dimension 2: Base); To what extent do we or customers have the influence to set price, and how should we use our potential influence? (Dimension 3: Influence); What combination of fixed and variable components do we want to employ when calculating the price, and what are our risk preferences regarding the fixed/variable balance? (Dimension 4: Formula); What should be the temporal extent of our offering? (Dimension 5: Temporal rights). In short, the model can enable new and innovative ways to think about price and what managers are actually offering their customers. On top of this, the model can be an aid for creative and innovative discussions by graphically 
displaying the repertoire of different possible price models that an organisation may deploy for its products and services. In workshops at Ericsson, it has served to explicitly illustrate the type of pricing of existing products and to highlight potential changes in pricing focus between scenarios for future market developments.

The model is not all-inclusive and there are some limitations that need to be taken into consideration when it is applied. Firstly, the model by itself presents only a snapshot of the different types of agreements that can be established between seller and buyer. To explore future and unforeseen customer requirements and demands (and risks that come with them) it would need to be combined with scenario analysis. Secondly, each agreement between seller and buyer is done in a wider context of a system of different actors (see e.g. $\mathrm{Ng}, 2010)$. This context can be defined as an ecology, i.e. surrounding the agreement is a "business ecosystem" of actors (e.g. vendors, competitors and partners) that influence each other over time. An organisation may have different price models depending on which actor is targeted and every type of price model sends signals to other actors in the ecosystem. To set an appropriate price is therefore not only related to the dimensions of the model but also connected to the current and future deals that the seller has with its actors in its business ecosystem, and possibly with deals conducted in other parts of the ecosystem. In this respect, when a firm selects a price model, it needs to orientate itself in the ecosystem, noting which price models are currently used and with which actor. This forms a basis for envisioning how price models can be altered and how such change influences the relationship between the different actors of the ecosystem (Teece, 2010). Altogether, this suggests that avenues for future research include exploring temporal aspects of the model as well as further understanding how price models interact with the wider business ecosystem in which they reside.

There are also other areas for future research. One avenue is to explore to what extent the five dimensions of the model are independent and if there are links that form patterns between the different positions. We have not made such discoveries, but further qualitative research targeted to explore that question could establish whether such patterns can be identified. Also, and as noted, this article is the product of a collaborative research project with the telecom company Ericsson. The collaboration project has shown that pricing is an area that influences many other departments besides the pricing department. Participants from departments such as Product Areas and Supply expressed that they now see more clearly how their work connects to pricing issues. This communicative quality of the model is important, given the notion that pricing is a vital strategic issue of concern for the organisation as a whole. Thus, another important subject for future research is what consequences price models have for the internal work of an organisation. For example, to what extent can and should employees far from pricing decisions consider different price models, how these models can affect their work and how their work can limit or enable different price models?

\section{Conclusion}

In a recent article devoted to the future of pricing research, $\mathrm{Ng}$ alleges that "Payments were traditionally exchange oriented-something given in exchange for something of value. Today, price models are less straightforward and the modern service economy has moved from exchange-based pricing to more sophisticated models that incorporate relational, temporal and behavioral issues" (Ng, 2010, p. 277). She contends that this is resulting in a world with a "myriad of pricing models" (p. 278) in which the organisations that can make sense of such complexity are presumably the ones with the greatest profits in their respective industry. This is the challenge that this article begins to address by proposing the SBIFT model. In doing so, we show how the price is connected to a collection of more implicit features of the price model. We have illustrated 
how the model helps exploring and uncovering such implicit features of current and future agreements between seller and buyer. Such strategic exploration of what ultimately constitutes the price model can aid an organisation to differentiate and re-invent its actual offering in ways that contribute to long-term survival.

\section{References}

Ahlström, P., Nilsson, F. and Olve, N.G. (2007) Mobilising and nurturing collaboration in research-the value of a focused imagination. International Journal of Action Research, 3(3), 297-323.

Amabile, T.M., Patterson, C., Mueller, J., Wojcik, T., Odomirok, P.W., Marsh, M. and Kramer, S.J. (2001) Academic-practitioner collaboration in management research: A case of cross-profession collaboration. Academy of management journal, 418-431.

Anderson, C. (2009) Free: The future of a radical price. Hyperion, New York.

Ariely, D., Lynch Jr, J.G. and Aparicio Iv, M. (2004) Learning by collaborative and individual-based recommendation agents. Journal of Consumer Psychology, 14(1 \& 2), 81-95.

Baden-Fuller, C. and Morgan, M.S. (2010) Business models as models. Long Range Planning, 43(2-3), 156171.

Bakos, Y. and Brynjolfsson, E. (1999) Bundling information goods: Pricing, profits, and efficiency. Management Science, 45(12), 1613-1630.

Balakrishnan, R. and Sivaramakrishnan, K. (2002) A critical overview of the use of full cost data for planning and pricing. Journal of Management Accounting Research, 14(1), 3-31.

Bartunek, J.M. and Louis, M.R. (1996) Insider/outsider team research. Sage Publications Thousand Oaks, CA.

Bhargava, H.K. and Choudhary, V. (2008) Research note--when is versioning optimal for information goods? Management Science, 54(5), 1029-1035.

Biswas, D. and Biswas, A. (2004) The diagnostic role of signals in the context of perceived risks in online shopping: do signals matter more on the web? Journal of Interactive Marketing, 18(3), 30-45.

Chartier, M. (2011). Internet mobile : Orange offrirait les meilleurs débits moyens. PCWorld.fr, 28 september 2011, < http://avc.blogs.com/a_vc/2006/03/my favorite bus.html> (accessed 09.11.11).

Cravens, D.W. and Piercy, N.F. (2009) Strategic Marketing. McGraw-Hill, Boston.

Diamantopoulos, A. (1991) Pricing: theory and evidence-a literature review. In M. J. Baker (Ed.) Perspectives on Marketing Management, pp. 63-192. John Wiley \& Sons, London.

Diamantopoulos, A. and Mathews, B. (1995) Making pricing decisions: A study of managerial practice. Chapman \& Hall, London.

Dixit, A., Whipple, T., Zinkhan, G. and Gailey, E. (2008) A taxonomy of information technologyenhanced pricing strategies. Journal of Business Research, 61(4), 275-283.

Dutta, S., Bergen, M., Levy, D., Ritson, M. and Zbaracki, M. (2002) Pricing as a strategic capability. MIT Sloan Management Review, 43(3), 61-66.

Dutta, S., Zbaracki, M. and Bergen, M. (2003) Pricing process as a capability: a resource-based perspective. Strategic Management Journal, 24(7), 615-630.

Fendt, J. and Kaminska-Labbé, R. (2011) Relevance and creativity through design-driven action research: Introducing pragmatic adequacy. European Management Journal, 29(3), 217-233.

Forman, H. and Hunt, J.M. (2005) Managing the influence of internal and external determinants on international industrial pricing strategies. Industrial Marketing Management, 34(2), 133-146.

Glaser, B.G. and Strauss, A.L. (1967) The discovery of grounded theory: strategies for qualitative research. Aldine, Chicago.

Gourville, J. and Soman, D. (2002) Pricing and the psychology of consumption. Harvard business review, 80(9), 90-96.

Heyman, J., Orhun, Y. and Ariely, D. (2004) Auction fever: the effect of opponents and quasi endowment on product valuations. Journal of Interactive Marketing, 18(4), 7-21.

Hinterhuber, A. (2004) Towards value-based pricing--an integrative framework for decision making. Industrial Marketing Management, 33(8), 765-778.

Hirshleifer, J., Glazer, A. and Hirshleifer, D. (2005) Price theory and applications: decisions, markets, and information. Cambridge University Press, Cambridge. 
Hrebiniak, L.G., Joyce, W.F. and Snow, C.C. (1989) Strategy, structure and performance: past and future research. In C. C. Snow (Ed.) Strategy, Organization Design and Human Reseource Management, pp. 3-54. Jai Press, Greenwich, Connecticut.

Ingenbleek, P. (2007) Value-informed pricing in its organizational context: literature review, conceptual framework, and directions for future research. Journal of Product \& Brand Management, 16(7), 441458.

Iyer, G. and Pazgal, A. (2003) Internet shopping agents: virtual co-location and competition. Marketing Science, 22(1), 85-106.

Janiszewski, C. and Cunha Jr, M. (2004) The influence of price discount framing on the evaluation of a product bundle. Journal of Consumer Research, 30(4), 534-546.

Johannisson, B., Gunnarsson, E. and Stjernberg, T. (2008) Gemensamt kunskapande: den interaktiva forskningens praktik. Växjö University Press, Växjö.

Johnson, G., Whittington, R., Scholes, K. and Pyle, S. (2011) Exploring strategy: text \& cases. Financial Times Prentice Hall.

Jonason, A. (2001) Innovative pricing. PhD Thesis. Royal Institute of Technology. Department of Industrial Economics and Management, Stockholm.

Kahneman, D. and Tversky, A. (1979) Prospect theory: an analysis of decision under risk. Econometrica: Journal of the Econometric Society, 47(2), 263-291.

Kim, J., Natter, M. and Spann, M. (2009) Pay what you want: a new participative pricing mechanism. Journal of Marketing, 73(1), 44-58.

Kung, M., Monroe, K.B. and Cox, J.L. (2002) Pricing on the Internet. Journal of Product \& Brand Management, 11(5), 274-288.

Learned, E.P., Christensen, C.R., Andrews, K.R. and Guth, W.D. (1969) Business policy: Text and cases. Irwin Homewood, IL.

Lindhult, E. (2008) Att bedöma och uppnå kvalitet i interaktiv forskning. In B. Johannisson, E. Gunnarsson \& T. Stjernberg (Eds.). Gemensamt kunskapande: den interaktiva forskningens praktik, pp. 333-347. Växjö, Växjö University Press.

Lord, B.R. (2007) Strategic management accounting. In T. Hopper, D. Northcott \& R. W. Scapens (Eds.) Issues in Management Accounting, pp. 135-154. Prentice Hall, London.

Lucas, M.R. (2003) Pricing decisions and the neoclassical theory of the firm. Management Accounting Research, 14(3), 201-217.

Malmer, S. (1996) Kommunal prissättning mot bakgrund av självkostnadsprinncipen. En problemanalys. Licentiate thesis. Gothenburg University, The School of Public Administration, Gothenburg.

Marn, M.V., Roegner, E.V. and Zawada, C.C. (2004) The price advantage. Wiley, Hoboken, N.J.

Mathew, M. and Nair, S. (2010) Pricing SAAS models: perceptions of business service providers and clients. Journal of Services Research, 10(1), 51-68.

Miles, M.B. and Huberman, A.M. (1984) Qualitative data analysis: a sourcebook of new methods. Sage, Beverly Hills.

Mintzberg, H. (2007) Tracking strategies: Toward a general theory. Oxford University Press, Oxford.

Monroe, K.B. (2003) Pricing : making profitable decisions. McGraw-Hill/Irwin, Boston.

Monroe, K.B. (2011) Some personal reflections on pricing research. Review of Marketing Research, 8(Special Issue-Marketing Legends), 209-241.

Munthe, A. (1930) The story of San Michele. Dutton, New York.

Nagle, T. (1984) Economic foundations for pricing. Journal of Business, 57(1), 3-26.

Nagle, T.T. and Hogan, J.E. (2006) The strategy and tactics of pricing : a guide to growing more profitably. Pearson/Prentice Hall, Upper Saddle River, N.J.

Ng, I.C.L. (2008) The pricing and revenue management of services: a strategic approach. Routledge, London.

$\mathrm{Ng}$, I.C.L. (2010) The future of pricing and revenue models. Journal of Revenue \& Pricing Management, 9(3), 276-281.

Normann, R. and Ramírez, R. (1993) From value chain to value constellation: designing interactive strategy. Harvard business review, 71(4), 65-77.

Parvinen, L.A., Windischhofer, R. and Gustafsson, M. (2010) Competitive advantage through value-based health care: the case of Metso Corporation. European Management Joumal, 28(3), 195-207.

Pasmore, W., Woodman, R. and Simmons, A. (2008a) Toward a more rigorous, reflective, and relevant science of collaborative management research. In A. Shani, S. Mohrman, W. Pasmore, B. Stymne \& N. Adler (Eds.). Handbook of collaborative management research, pp. Sage, Thousand Oaks, CA. 
Pasmore, W.A., Stymne, B., Shani, A., Mohrman, S.A. and Adler, N. (2008b) The promise of collaborative management research. In A. Shani, S. Mohrman, W. Pasmore, B. Stymne \& N. Adler (Eds.). Handbook of collaborative management research, pp. 7-31. Sage, Thousand Oaks, CA.

Peitz, M. and Illing, G. (2006) Industrial organization and the digital economy. MIT Press, Cambridge, Mass.

Piercy, N., Cravens, D. and Lane, N. (2010) Thinking strategically about pricing decisions. Journal of Business Strategy, 31(5), 38-48.

Porter, M.E. (1985) Competitive advantage: creating and sustaining superior performance. Free Press, New York.

Rao, V.R. (1984) Pricing research in marketing: The state of the art. Journal of Business, 57(1), 39-60.

Schedler, K., Summermatter, L. and Schmidt, B. (2004) Managing the electronic government: from vision to practice. Information Age Pub Inc, Greenwich, CT.

Shani, A., David, A. and Willson, C. (2004) Collaborative research: alternative roadmaps. In A. N., A. Shani \& A. Styhre (Eds.). Collaborative research in organizations, foundations for learning, change and theoretical development, pp. 83-100. Sage, Thousand Oaks, CA.

Shani, A.B., Coghlan, D. and Coughlan, P. (2008) Handbook of collaborative management research. Sage Publications.

Shapiro, C. and Varian, H.R. (1999) Information rules: a strategic guide to the network economy. Harvard Business School, Boston, Mass.

Shipley, D. and Jobber, D. (2001) Integrative pricing via the pricing wheel. Industrial Marketing Management, 30(3), 301-314.

Shipley, D.D. (1981) Pricing objectives in British manufacturing industry. The Journal of Industrial Economics, 29(4), 429-443.

Susarla, A., Barua, A. and Whinston, A. (2009) A transaction cost perspective of the" Software as a Service" business model. Journal of Management Information Systems, 26(2), 205-240.

Teece, D.J. (2010) Business models, business strategy and innovation. Long Range Planning, 43(2-3), 172194.

Turing, A.M. (1950) Computing machinery and intelligence. Mind, 59(236), 433-460.

Van De Ven, A. (2007) Engaged scholarship: a guide for organizational and social research. Oxford University Press, Oxford.

Van De Ven, A.H. and Johnson, P.E. (2006) Knowledge for theory and practice. Academy of Management Review, 31(4), 802-821.

Werr, A. and Greiner, L. (2008) Collaboration and the production of management knowledge in research, consulting, and management practice. In A. Shani, S. Mohrman, W. Pasmore, B. Stymne \& N. Adler (Eds.). Handbook of collaborative management research, pp. 93-118. Sage, Thousand Oaks, CA.

Westelius, A., Petri, C., Cöster, M., Nilsson, F. and Olve, N. (2010) Prismodeller - en taxonomi. Ekonomiska Samfundets Tidskrift, 2010(3).

Wilson, F. (2006). Jared: My Favorite Business Model. $<$ http://avc.blogs.com/a vc/2006/03/my favorite bus.html> (accessed 09.11.11).

Zeithaml, V. (1988) Consumer perceptions of price, quality, and value: a means-end model and synthesis of evidence. The Journal of Marketing, 52(3), 2-22.

\section{FOOTNOTES}

\footnotetext{
${ }^{1}$ The collaborative research project provided deep insights into Ericsson's complex issues of pricing. However, in order to attain access to the organisation the researchers had to sign a confidentiality agreement that limits the inclusion of Ericsson's pricing strategies in external publications (partly due to the current fierce competition within their industry). This is also why the model is not applied to Ericsson's offerings in Section 4.2. Nevertheless, the paper reflects the most common problems that they, as well as other organisation, face in setting appropriate price on their offerings.
} 
${ }^{2}$ In the research project, several other organisations' pricing was analysed to increase the validity and robustness of the model (see method section), but most of these cases would need more complex and extensive narratives as they are less well-known (and are therefore not included).

${ }^{3}$ For example, a recent test of achieved speed with 3.7 million observations demonstrates that Orange outperforms its competitors by far (Chartier, 2011). 